\title{
Santidade, Militarização e InstituCionalização Textual de SÃo Jorge nos TerritóRIos da Coroa de ARAgÃo
}

Sanctity, Militarization, and Textual Institutionalization of Saint George in the Crown of Aragon

Luciano J. Vianna*

lucianojvianna@hotmail.com

RESUMO: Nossa intenção neste artigo é recuperar a presença de São Jorge na Coroa de Aragão, principalmente nos relatos literários em que o mesmo foi representado durante o medievo. Para isso, abordamos as perspectivas da memória cultural destacadas por Jan Assmann. Inicialmente contextualizamos brevemente a história do personagem, destacando os principais momentos em que foi representado e quais autores fizeram referência à sua existência, apresentando as realizações dos condes-reis da Coroa de Aragão e principalmente o longo processo em que este personagem foi acrescentado à memória coletiva deste território. Também apresentamos a oposição existente entre Santiago Matamoros e São Jorge, que serviu para consolidar a presença deste nas terras da coroa aragonesa. Por fim, analisamos sua institucionalização textual produzida nos territórios da Coroa de Aragão e os principais temas aos quais fora associado. Com isso, pretendemos esboçar a presença do santo nos âmbitos culturais da religiosidade, da guerra e como parte da história institucional da Coroa de Aragão.

PALAVRAS-CHAVE: São Jorge, literatura, Coroa de Aragão

ABSTRACT: In this article, our intention is recover the presence of St. George in the Crown of Aragon, mainly in the literary sources, which the character was represented during the Middle Ages. We utilize the perspectives of the cultural memory studied by Jan Assmann. In a first moment, we contextualize briefly the history of St. George, highlighting the mainly moments in which was represented and which authors referred to this existence. In a second moment, showing the acts of the counts-kings of Aragon, and mainly the large process in which this character was put together in the collective memory of this territory. In this sense, we also show the opposition between Santiago Matamoros and St. George, which served to consolidate his presence in the territories of the Crown of Aragon. Finally, we analyse his textual institutionalization in the Crown of Aragon and the mainly themes which was associated. In this sense, our intention is to highlight the presence of the saint in the cultural environment of the sanctity, war, and as part of the institutional history of the Crown of Aragon.

KEYWORDS: St. George, Literature, Crown of Aragon.

\section{Primeiros indícios de São Jorge}

\footnotetext{
* Doutor em História Medieval pela Universitat Autònoma de Barcelona (UAB). Pesquisador do Programa Nacional de Pós-Doutorado (PNPD) da CAPES. Professor colaborador voluntário do Programa de Pós-Graduação em História da Universidade Federal de Sergipe (UFS).
} 
Capadócia, século III d. C. Um soldado romano chamado Jorge, nascido por volta do ano 270 na região de Dióspolis, confessou a sua conversão ao Cristianismo e foi martirizado por volta do ano 303 durante o governo do imperador Diocleciano (284-305). Esta é a pequena história de São Jorge, a qual é, de acordo com Canellas López (1966-1967, p. 7-22) de historicidade muito discutida. Atualmente, sabe-se que existem diversos testemunhos escritos e iconográficos, os quais foram encontrados principalmente no Oriente, que confirmam a realidade histórica deste personagem. De acordo com Sayrach i Fatjó (1996, p. 27-30, 37), é provável que o seu culto tenha começado depois de sua morte e se difundiu pelas comunidades cristãs da época.

No que se refere aos testemunhos textuais, Eusébio de Cesaréia (264-339), o qual foi uma referência na produção hagiográfica de sua época e que escreveu uma história dos mártires durante o império de Diocleciano, não fizera nenhuma referência a São Jorge (CANELLAS LÓPEZ, 1966-1967, p. 7-22). Por outro lado, outras investigações destacam que o autor de Cesaréia, ainda que não tenha feito referência diretamente a São Jorge, fez uma alusão a um mártir anônimo que destruiu o édito imperial diante do imperador Diocleciano (SAYRACH I FATJÓ, 1996, p. 28).

Outros personagens como Santo Agostinho (354-430) e Isidoro de Sevilha (c. 560636) propagaram a vida de São Jorge através dos seus escritos, tendo como base sobretudo a lenda do dragão (BARRIGA I PÉREZ, 2006, p. 49), uma das mais difundidas com o passar dos séculos. De acordo com Canellas López (1966-1967, p. 7-22), a difusão desta lenda teve como ápice o século XI, e alcançou êxito durante o século XIII com a Legenda Áurea de Jacopo de Varazze (c. 1230-1298), a qual obteve uma considerável receptividade nas terras da Coroa de Aragão (JAUME DE VORÀGINE, Llegenda Àuria, p. 41, 47-50).

Segundo Anglès (1961, p. 41-65), desde o século VI o santo já era cultuado nos territórios da atual Itália, Sicília e na antiga Gália. Em Roma, durante o pontificado do papa Leão (682-683) foi construída uma basílica para os santos Sebastião e Jorge, a qual foi continuada pelo papa Zacarias (741-752) no ano 750 (BARAUT, 1997, p. 137-142).

Durante os séculos XI e XII surgiu a representação do santo como cavaleiro. Esta imagem o apresentou como cruzado e guerreiro, participando principalmente no processo de luta contra os muçulmanos. Devido às Cruzadas e à presença de cristãos no Oriente, a representação do santo incentivou a implementação do seu culto por toda Europa ocidental (SAYRACH I FATJÓ, 1996, p. 28). Assim, este contexto auxiliou na representação de Jorge nas crônicas como a de um cruzado que protegia e auxiliava o exército cristão nos principais momentos das batalhas.

Esta rápida introdução a respeito da origem oriental do santo, sua representação nos primeiros séculos do medievo, até sua entrada e estabelecimento no ocidente medieval 
como cavaleiro, serve para nos alertar sobre a mudança de perspectiva que ocorreu sobre o seu personagem. Assim, é correto afirmar que o mesmo estava em constante transformação através da memória dos que lhe representavam, os quais adaptavam as características do santo à cultura social do momento. Dessa forma, podemos afirmar que São Jorge fez parte, nestes primeiros esboços sobre sua vida, de uma memória cultural.

\section{A memória cultural}

Segundo Jan Assmann (2005, p. 125-133), a memória cultural é um conceito coletivo que está diretamente relacionado à estrutura interativa de uma dada sociedade e que se mantem por meio de retransmissões e práticas culturais. Segundo este autor, algumas das funções da memória cultural enquanto agente de uma sociedade é preservar o conhecimento já existente, conhecimento este que dá origem a um grupo que tem consciência respeito à sua unidade e peculiaridade; reconstruir o passado através de apropriações, críticas, preservações e transformações; utilizar textos, imagens e rituais para materializar e transmitir uma herança culturalmente institucionalizada; depender de um tipo de suporte para ser difundida; ser uma referência para a sociedade, pois possui em seu conteúdo características formativas e normativas; contem em si as práticas comuns, as reflexões sociais de explicação, distinção, interpretação, crítica, censura e controle, e representação da imagem do grupo ao qual está associada (ASSMANN, 1995, p. 125-133).

De acordo com esta perspectiva teórica, partimos do pressuposto que a vida de São Jorge estava imbricada na sociedade medieval da Coroa de Aragão e foi transmitida e retransmitida através textos, imagens e rituais, sempre organizados pelo grupo que formulava esta memória cultural, reconstruindo o passado por meio de apropriações e adaptações da imagem deste personagem. Assim, nossa intenção neste artigo é, a partir das reflexões teóricas sobre a memória cultural explicadas anteriormente, aproximar-nos à construção da memória cultural sobre São Jorge nos territórios da Coroa de Aragão, observando as informações referentes ao seu culto, as iniciativas e ações dos condes-reis da Coroa de Aragão, a oposição a Santiago Matamoros e sua institucionalização textual estabelecida na documentação produzida na Coroa de Aragão.

\section{O culto de São Jorge na Coroa de Aragão}

Honor a una tradición georgiana que en los últimos cinco siglos inspiró a los artistas (...). Honor a una devoción que desde el siglo XIII al menos, tuvo 
carta de naturaleza en la Corona de Aragón, inspiró cofradías nobiliarias y también cultos religiosos, fiestas sociales, parabienes, amor a las rosas, actos literarios; el señor San Jorge, prototipo de mártir y caballero espiritual y desinteresado, fabuloso y sugestivo con la fuerza imaginativa de tantos santos orientales, creó en estas tierras aragonesas emoción religiosa y patriótica; arraigado en la conciencia popular, amalgamó gentes de muchas tierras y engendró el sentimiento de patria aragonesa (CANELLAS LÓPEZ, 1966-1967, p. 7-22).

A conclusão de Canellas López (1966-1967, p. 7-22) é uma síntese sobre o significado de São Jorge, de modo que devemos considerar que sua existência e influência no imaginário é motivo suficiente para que seja estudado como um fenômeno histórico há tempos pertencente às terras da antiga Coroa de Aragão. Analisando esta perspectiva de acordo com o nosso objeto de estudo, devemos recordar que em diversos territórios São Jorge foi considerado como patrono ou protetor, como o Reino da Inglaterra, o Reino de Portugal, etc..., o que reforça a sua importância histórica não somente nos círculos peninsulares ibéricos, mas também em outros territórios.

Desde a primeira metade do século XI a festividade de São Jorge já estava registrada nos sacramentários produzidos no Principado da Catalunha. Neste mesmo século foram construídos os primeiros altares e igrejas sob a proteção do santo, o que contribuiu para estabelecer seu culto neste território. Neste contexto, foram importantes as iniciativas individuais de três personagens prestigiosos e de autoridade política que contribuíram para a difusão do culto do santo: o abade Oliba de Ripoll (c. 971-1046), o bispo Eribau da Sé de Urgell (c. 1036-1040) e o fundador da dinastia do viscondado de Ager, Arnaldo Mir de Tost (c. 1000-1072), o qual foi um dos primeiros responsáveis por associar o santo aos ideais cavalheirescos na luta contra os muçulmanos. O mais importante a ser destacado são as conclusões que Cebrià Baraut (1997, p. 137-142) apresentou sobre as origens do culto de São Jorge nas terras do Principado: de acordo com este autor 1) as hipóteses sobre a importação do culto do santo diretamente do oriente devem ser descartadas; 2) o culto do santo foi recebido nos territórios do Principado através da divulgação da liturgia romana; 3) o bispado de Urgell foi provavelmente o primeiro território em que a festividade de São Jorge foi introduzida e 4) a inclusão do nome do santo nos calendários litúrgicos foi crucial para a expansão do seu culto.

Entre os diversos condes-reis da Coroa de Aragão que the prestaram homenagem estão Pedro o Católico (1196-1213), Jaime o Conquistador (1213-1276), Jaime o Justo (12911327), Afonso o Benigno (1327-1336), Pedro o Cerimonioso (1336-1387), João o Caçador (1387-1396) e Martinho o Humano (1396-1410). De acordo com Anglès (1961, p. 41-65), entre as ações destes condes-reis por todo o território da Coroa de Aragão encontramos o estabelecimento de confrarias e priorados, a construção de castelos, capelas e a institucionalização de ordens de cavalaria. 
Dentre as diversas ordens criadas houve por exemplo a Ordem de São Jorge da Alfama, criada em 1201 por Pedro o Católico. Ainda que depois de alguns anos se unificou com a Ordem de Santa Maria de Montesa, a Ordem de São Jorge da Alfama foi um dos principais meios de difusão do culto ao santo no território da Coroa de Aragão (ALVIRA CABRER, 2010, p. 426-429). Ademais, segundo Cingolani (2014, p. 114-115), foi uma das primeiras ordens de cavalaria próprias da Coroa de Aragão, impulsando, assim, a luta contra os muçulmanos. Em 1353 Pedro IV de Aragão, também conhecido como o Cerimonioso, criou a Confraria dos Cavaleiros da Ordem de São Jorge e na década de 1380 a Ordem da Cavalaria de São Jorge. A presença do santo neste território também foi difundida através dos almogávares, os quais tinham como grito de guerra o nome "São Jorge", juntamente com o de “Avante, Aragão!" (BARRIGA I PÉREZ, 2006, p. 80, 83).

Já fazendo parte permanente do imaginário, anos depois o santo foi representado em outros momentos da história da Coroa, como quando o rei Pedro o Cerimonioso diante da guerra contra a Coroa de Castela ordenou aos seus bispos que fizessem diariamente missas a São Jorge para conseguir suas intervenções nas batalhas, como bem destacou Lafuente Gómez (2008, p. 427-444).

Tabela 1:

Principais datas sobre a relação de São Jorge e os territórios da Coroa de Aragão

\begin{tabular}{|c|c|}
\hline Ano & Evento \\
\hline 1096 & Patrono do Reino de Aragão \\
\hline 1343 & Patrono do Reino de Valência \\
\hline 1378 & Pntrodução da festa de São Jorge no Principado da Catalunha \\
\hline 1407 & Cnício dos procedimentos para estabelecer São Jorge como patrono do Principado da \\
\hline 1436 & Festa oficial de São Jorge no Principado da Catalunha \\
\hline 1456 & Reconha oficial de São Jorge em Lérida \\
\hline 1458 & Reafirmação de São Jorge como patrono da Coroa de Aragão \\
\hline 1467 & Gregório XIII concede a indulgência aos que visitem a capela de São Jorge \\
\hline
\end{tabular}


Com os anos, o culto ao santo adquiriu um aspecto institucional e foi incorporado ao calendário festivo nos diferentes reinos e territórios da Coroa de Aragão. Por exemplo, desde 1378 sua festa foi instituída em Barcelona, a qual foi oficializada em 1456, quando Calixto III (1455-1458), primeiro papa valenciano da história, o declarou como patrono do Governo da Catalunha (ver tabela 1) (BARRIGA I PÉREZ, 2006, p. 85).

Além disso, ainda que a festa tenha sido estabelecida oficialmente somente a partir de meados do século XV, o Dietari, documento no qual eram anotados todos os acontecimentos diários relacionados ao governo do Principado da Catalunha, confirma que desde muito tempo já se celebrava o culto ao santo no dia 23 de abril, pois o primeiro registro deste documento é do ano 1412 (Dietaris de la Generalitat de Catalunya, 1994, p. 2).

Desta forma, é correto afirmar que a transmissão e o estabelecimento da imagem de São Jorge no território da Coroa de Aragão ocorreu através de diversos meios, os quais favoreceram a paulatina elaboração da memória cultural deste personagem relacionada a este território. Neste contexto, seguindo a proposta de Jan Assmann (1995, p. 125-133), a memória cultural compreende um corpo de textos, imagens e rituais, os quais podem ser utilizados e servem para estabilizar e transmitir a autoimagem de uma sociedade. No caso da vida de nosso personagem principal, existe um vasto e considerável corpus documental, principalmente as manifestações culturais imagéticas. No caso do tema deste artigo, ou seja, a manifestação cultural e literária da vida de São Jorge relacionada aos territórios da Coroa de Aragão, a mesma fora utilizada em diferentes contextos históricos, o que serviu para difundir e estabelecer sua presença de forma definitiva em meio aos diferentes contextos. De todas as formas, estamos diante de um fenômeno que se desenvolveu lentamente, desde as suas primeiras menções nos documentos até o seu estabelecimento oficial e definitivo como personagem partícipe da memória histórica da Coroa de Aragão.

\section{Fortalecendo a identidade: a oposição Santiago Matamoros}

Em um território fronteiriço, social e culturalmente diversificado como era a Península Ibérica durante os séculos do medievo, a constante luta entre cristãos e entre cristãos e muçulmanos favoreceu constantemente a construção da imagem do outro. No caso do presente artigo, um dos santos combatentes contemporâneos à época de São Jorge era Santiago, conhecido também como Jacobo Peregrino e Santiago Matamoros, de acordo com as necessidades contextuais.

Desde o século IX, precisamente na batalha de Clavillo (859), Santiago era reconhecido como o protetor dos cristãos intervindo nas lutas contra os muçulmanos (MÁRQUEZ VILLANUEVA, 2004, p. 165, 188-189). Da mesma forma que a manifestação 
cultural de São Jorge, devemos considerar que o seu mito foi sendo modificado com o passar do tempo, de acordo com as diferentes circunstâncias históricas e culturais em que se manifestava (DOMíNGUEZ GARCÍA, 2008, p. 18).

Em um primeiro momento, o santo foi "utilizado" desde uma perspectiva da peregrinatio, a qual durante o medievo era considerada como a realização de uma viagem, a sensação de ser um estrangeiro em um outro lugar, a realização de um esforço espiritual e o ato de usufruir de um período de festa e celebração (SOT, 2003, p. 646-654). E foi dentro deste quadro contextual que se desenvolveu inicialmente o culto a Santiago na Península Ibérica.

Os resultados da investigação de Domínguez García relacionados à mudança de perspectiva do personagem Jacobo Peregrino para Santiago Matamoros indicam que o símbolo de Santiago foi um fator importante para a integração social e substituiu o caráter simbólico de outros personagens, como por exemplo Pelayo, el Cid ou Afonso I. Por outro lado, esta união social não se desenvolveu de uma forma completa, já que no território da Coroa de Aragão o culto a São Jorge teve uma influência maior. De todas as formas, é fato que a construção da ideia de Reconquista também foi absorvida pelo culto de Santiago, fazendo com que o mesmo fosse representado como símbolo inseparável deste processo histórico. Segundo Domínguez García (2009, p. 48-49, 50-55), esta integração, ao redor da qual surgiu o símbolo de Santiago, foi produzida no contexto da luta contra os muçulmanos e foi representada em diversas fontes da época, como por exemplo a Concordia de Antealtares, a Historia Silense, a Chronica Adefonsi Imperatoris e o Poema de Almería.

No começo do século XV, Santiago era representado pela iconografia como um guerreiro (MÁRQUEZ VILLANUEVA, 2004, p. 183-184). Foi precisamente esta representação que foi transferida pelos peninsulares nos primeiros contatos com as terras americanas, como pode ser visto em diversos relatos e crônicas produzidas na primeira metade do século $\mathrm{XVI}$, transformando a conquista destes territórios em uma extensão da Reconquista na Península Ibérica (SOUZA, 2010, p. 89-90).

Um detalhe que chama a atenção refere-se ao esmaecimento do mito de Santiago no território espanhol. De acordo com Márquez Villanueva (2004, p. 271-274), toda a construção do imaginário coletivo referente a Santiago tinha em si mesma o princípio de sua destruição, já que este personagem estava destinado a auxiliar no combate contra os muçulmanos presentes no território peninsular, de forma que por volta do século XVI o culto às suas relíquias já estava em um processo de decadência.

No que se refere à sua relação com a Coroa de Aragão, devemos destacar a perspectiva opositora ao patrono destas terras, ou seja, São Jorge. O desenvolvimento do culto aos dois santos foi desenvolvido a tal ponto que houve contextos em que os mesmos 
foram utilizados no mesmo confronto. Por exemplo, no que se refere às relações políticas entre a Coroa de Castela e o Reino de Portugal sobre a sucessão do trono português entre 1383 e 1385, Santiago e São Jorge foram utilizados respectivamente para os seus propósitos particulares. Por exemplo, Fernão Lopes, em sua Crônica de D. João I, identifica os castelhanos como inimigos, o mesmo qualitativo dado aos mouros, ou seja, os muçulmanos:

De guisa que, como no começo desta obra nomeamos fidallgos alguus que ao Comde do Hamrrique ajudarom a gaanhar a terra aos Mouros; assi neeste segumdo vollume diremos huus poucos dos que ao Mestre forom companheiros em deffemder o rreino de seus emiigos (FERNÃO LOPES, Crónica de D. João VI, CLIX, p. 340).

Devemos recordar que foi precisamente neste contexto que se desenvolveu o culto a São Jorge nas terras do reino português. A aliança entre o Reino de Portugal e o duque de Lancaster, João de Gante (1340-1399), teve como resultado a substituição do grito "Santiago" durante as batalhas pelas insígnias de São Jorge, principalmente a cruz vermelha, fato que teve um significado não somente religioso e propagandístico, mas também prático e tático, já que serviu para não confundir os arqueiros ingleses durante as batalhas (SÁNCHEZ SESA, 2004, p. 447-464). Desta forma, podemos concluir que este culto se desenvolveu não somente de uma forma autônoma, ou seja, elaborada dentro de um imaginário coletivo, mas também em um contexto de oposição ao outro, neste caso, Santiago, mediante um enfrentamento direto.

Para o tema deste artigo, ou seja, a identificação de São Jorge com os territórios da Coroa de Aragão, é interessante sintetizar brevemente a comparação entre São Jorge e Santiago Matamoros em três momentos: 1) desenvolvimento inicial dos mitos nos seus respectivos territórios de influência mediante a produção de textos, imagens, etc... e a difusão no imaginário coletivo; 2) projeção dos mitos e a sua utilização em processos em que estes respectivos territórios se encontravam, ou seja, o processo de Reconquista nas terras peninsulares; 3 ) divergência concomitante entre os mitos: ao mesmo tempo em que o culto a Santiago começou o seu declínio na coroa castelhana e a sua transferência para as terras americanas, o mito de São Jorge passou por um processo de estabilização na Coroa de Aragão e começou a sua institucionalização.

A presença de um símbolo catalizador como o de Santiago Matamoros também foi importante para o desenvolvimento e fortalecimento do culto de São Jorge nas terras da Coroa de Aragão, não somente para reforçar o seu culto e difusão entre os fiéis, mas também para consolidar e confirmar seu personagem como um símbolo da identidade deste território, a qual foi representada em diversos documentos, como veremos no tópico seguinte. 
Os documentos produzidos na Coroa de Aragão: a instituição textual de São Jorge (c. 12701500)

Arraigado na mentalidade coletiva social, a presença de São Jorge nos territórios da Coroa de Aragão proporcionou uma intensa produção artística e literária (CINGOLANI, 2014 , p. 127, 129). Em seus estudos sobre a memória, Pierre Nora (1984) fez uma importante afirmação sobre a transformação de informações da memória em um bem comum e como herança coletiva nas sociedades:

la transformation en bien commun et en héritage collectif des enjeux traditionnels de la mémoire elle-même (...) sur le mode d'une sensibilité renouvelée à la singularité (...), combinée d'une adaptation nécessaire aux conditions nouvelles (NORA, 1984, p. 647-658).

Pierre Nora destaca a importância da transformação da memória, pertencente à uma determinada sociedade, em bem comum, a qual adapta esta mesma memória às suas novas condições. Considerando todo o desenvolvimento da representação de São Jorge na Coroa de Aragão, podemos afirmar que o caso do santo é exemplar no que diz respeito a esta adaptação.

É certo que um dos momentos chave da construção territorial da Coroa de Aragão ocorreu durante o reinado de Jaime I (1214-1276), o qual realizou um considerável processo de expansão dos territórios da coroa ao conquistar os territórios muçulmanos de Maiorca (1229), Valência (1238) e auxiliando seu genro, Afonso X, na conquista do Reino de Múrcia (1266). E os cronistas, no intuito de não somente registrar mas também proporcionar uma identidade e singularidade a estas conquistas, destacaram o papel de São Jorge nas mesmas. Por exemplo, na singular passagem da conquista da cidade de Maiorca em 1229 presente no Livro dos Feitos destacada a seguir São Jorge, já é considerado presente na memória cultural do território, sendo visto como o primeiro cavaleiro que entrou no assalto à cidade muçulmana de Medina Mayūrqa:

Segons ens contaren els sarraïns, deien que van veure entrar primer a cavall um cavaller blanc amb armes blanques. I hem de creure que devia ésser sant Jordi, car en els llibres d'història llegim que l'han vist moltes vegades en altres batalles entre cristians i sarraïns (Llibre dels Fets del Rei Em Jaume, cap. 84).

Entre os anos de 707 e 1229, Maiorca estivera sob o domínio muçulmano. No momento da conquista cristã a ilha era governada pelo wali Abu-Yahya (1208-1229), representante da dinastia Almôada, o qual estava no governo desde 1208. Antes dele 
governava a ilha a dinastia dos Banu Ganiya, representada pelo último emir almorávida da ilha, Abd Allah ibn Ishaq ibn Ganiya (?-1203). De acordo com Casasnovas Camps (1998, p. 134-135), na hierarquia política muçulmana o califa nomeava os walis de cada território e o fato de Abu-Yahya permanecer por tanto tempo no poder reflete a crise política pela qual passava a dinastia Almôada, principalmente desde a derrota de Las Navas de Tolosa (1212).

A conquista de Maiorca foi um dos eventos mais destacados do reinado de Jaime I. De acordo com Cingolani (2008, p. 37), esta conquista tornou o rei conhecido no âmbito peninsular e territorial europeu da época, destacando e difundindo o conhecimento do seu feito de armas pelos demais reinos e coroas. No fragmento do Livro dos Feitos destacado anteriormente podemos ver o relato sobre a aparição de São Jorge no momento da entrada do exército cristão na conquista da cidade. Passados quase três meses de assalto à ilha, o relato da aparição do santo cavaleiro com suas vestes brancas e seu cavalo branco justamente no momento do assalto à cidade é uma representação da tentativa de associar o santo ao contexto da Reconquista, associando-o ao exército cristão. É necessário destacar também as informações que a narrativa nos fornece, como, por exemplo, a afirmação de que o santo fora visto em outras histórias e em outras batalhas e que fora visto não somente por cristãos, mas também por muçulmanos. Considerando o diversificado contexto social e cultural da Coroa de Aragão, tal afirmação é uma tentativa por parte do cronista em estabelecer o santo como partícipe antigo do território, presente também nos manifestos literários do território.

Entretanto, tal aparição não se resumiu somente à conquista de Maiorca. Durante a longa empresa da conquista de Valência (1229-1245) também foi registrada a aparição do santo em momentos importantes da conquista na Crónica de San Juan de la Peña:

porque se dize que como el avies enviado algunos nobles et cavalleros en el Regno de Valencia, yes assaber, el noble don Bernat Guillem d'Entença et de otros cavalleros de Aragón et de Catalunya et fuessen en un pueyo qui agora es clamado Santa María del Puyg et toda la morisma vinies contra ellos en la batalla, qui entre ellos fue muyt grant, les apareció sant Jorge con muytos cavalleros de parada qui los ayudó a vencer la batalla, por la qual ayuda ningún christiano no hi murió (Crónica de San Juan de la Peña, 1985, p. 95).

O fragmento destacado refere-se a um importante momento da conquista do território valenciano: a batalha del Puig, como ficou conhecida, refere-se a um importante local estratégico para a instalação do exército da Coroa de Aragão e que auxiliou na conquista da cidade de Valência em 1238. Novamente vemos a presença de São Jorge auxiliando os cavaleiros cristãos na batalha contra os muçulmanos. Deve-se destacar que o rei Jaime I não participara desta batalha, ao contrário como ocorrera em Maiorca, quando estava na liderança das operações, mas mesmo assim o santo aparecera, o que reforça a 
ideia de que o cronista associou o santo ao território, e não ao rei, identificando-o, dessa forma, como uma manifestação intrínseca ao território. Esta diferença em relação à conquista de Maiorca talvez possa ser explicada pelo fato de que o Livro dos Feitos fora composto no final do reinado de Jaime I, entre 1270 e 1276, e a Crónica de San Juan de la Peña aproximadamente em 1342, durante o reinado de Pedro o Cerimonioso, em um contexto em que a presença de São Jorge no imaginário coletivo estava bem mais arraigada, o que possibilitou sua "associação" também ao território valenciano. Devemos recordar também que em 1343 São Jorge fora estabelecido como patrono do Reino de Valência (ver tabela 1), ou seja, um ano após a composição da Crónica.

Ainda sobre o reinado de Pedro o Cerimonioso deve ser destacada a presença de São Jorge nas Ordinacions de la Casa i Cort, promulgadas pelo rei em 1344:

Ordonam encara que de IIII en IIII anys, en la festa de sancta Maria d'agost, III cortines de cendat o de drap de seda e IIII coixins de vellut o de drap de seda, dos grans e dos altres cayrats pus pochs, e I drap de seda qui les parets de l'oratori cobra, e II draps de lana qui-Is banchs e lo sòl cobren, d'aquella color que a Nós pus plasent será ornats del nostre senyal real o del senyal antich dels rey d'Aragó o de sent Jordi, sien fets i honradamente apparellats (Ordinacions de la Casa i Cort de Pere el Cerimoniós, 2009, p. 166).

As Ordinacions, que na verdade são uma cópia das Leges palatinae regni Maioricarum instituídas por Jaime III de Maiorca (1324-1343), representam um grande esforço por parte de Pedro o Cerimonioso em tentar organizar, de uma forma eficiente, a corte e também diversas outras jurisdições do reino (TASIS I MARCA, 1979, p. 33). No documento há a referência a São Jorge ao sinal heráldico do mesmo, muito utilizado na época, o qual serviria para ornamentar a corte no dia de Santa Maria de Agosto, ou seja, o dia da Assunção de Nossa Senhora, associando o santo ao culto mariano, que nessa época, segundo Le Goff (2003, p. 106-109), havia alcançado um status superior excepcional. Devemos recordar que no caso o "senyal antich dels rey d'Aragó o de sent Jordi" refere-se à cruz vermelha, a qual estava presente no estandarte real aragonês desde o século XI (DAVIES, 2013, p. 203).

Raimundo Muntaner (1265-1336) em sua Crônica (c. 1325-1328) também relata a presença do santo em meio às futuras conquistas dos condes de Barcelona e reis de Aragão, em um sermão preparado em 1322 para o infante Afonso, o futuro Afonso o Benigno, filho do rei Jaime II o Justo:

E que'I nom d'Aragó ne sia exalsats,

E que Pisans ne altres nols puscha falsedats

Bastir, ne hordonar, e sent jordi alats 
De l'alt senyor infant li sia acompanyats

(Crònica de Ramon Muntaner, 1971, cap. 272).

Ao escrever estes versos, Raimundo Muntaner desejava aconselhar o infante Afonso na expedição que este faria no ano seguinte (1323) contra a ilha de Sardenha. De acordo com Armangué i Herrero (2001, p. 15-28), este sermão é a primeira manifestação historiográfica que relaciona a terra sarda com a literatura produzida na Coroa de Aragão. $E$ também nesta expressão literária novamente encontramos São Jorge, dessa vez associado a uma futura conquista, na qual acompanharia o representante da Coroa de Aragão.

Outro exemplo de aparição do santo na literatura medieval da Coroa de Aragão é dado por São Vicente Ferrer (1350-1419), que em um dos seus sermões destacou a ajuda de São Jorge ao rei Jaime I:

Esta solemnitat anual que es fa de mossènyer sent Jordi, és por les grans ajudes que féu en la conquesta de la ciutat e Regne de València, e per ço serà lo sermó de sent Jordi (VICENT FERRER, Sermons de Quaresma, 2003, p. 188).

Nas palavras de São Vicente Ferrer observamos que São Jorge ajudou a conquistar não somente a cidade de Valência, mas também o reino valenciano, o que significa a interpretação de sua ajuda nas conquistas se estendeu por todo o reino em direção ao sul peninsular.

Poucos anos depois, em 1462, no contexto inicial da Guerra Civil Catalã (14621472), o santo foi reafirmado como patrono, de acordo com o Dietari:

Dissabte, a xvii. Aquest die fonch feta crida pública per la ciutat de Barchinona que la festa de sent Jordi fos colta generalment per tothom, com la Cort General del principat de Cathalunya, qui de present se celebre en la claustra de la Seu de la dita ciutat, ne hagués feta novament constitució (Dietaris de la Generalitat de Catalunya, 1994, p. 130-131).

Vemos aqui a institucionalização da festa de São Jorge nos territórios do Principado da Catalunha, relembrando, em um contexto inicial da Guerra Civil Catalã, a qual opôs o Principado da Catalunha contra as pretensões do rei João II de Aragão de controlar politicamente o território.

Em outra fonte da época, conhecida como Sumari d'Espanya, composta entre 1470 e 1500, a imagem do rei Jaime I e de São Jorge foram novamente associadas: 
Aprés de aquest rey Pere, regnà en rey d'Aragó e compte de Barcelona e en la baronia de Monpeller En Jaume, fill seu, apellat Sant. Aquest rey fonch molt aventurós contra moros, car jamés perdé batalla ell ni ses gents, en cars que ell no y fos en persona, e en les batalles que ell agué ab moros fonch vist molt[e]s vegades lo benaventurat Sant Jordi en ajuda sua (Sumary d'Espanya, 2000, p, 212).

A novidade desta fonte é que ela não somente destaca a presença de São Jorge auxiliando o rei Jaime nas batalhas, mas também afirma que o Conquistador era considerado santo. Dessa forma, o documento é uma manifestação da presença de São Jorge associada à de outro personagem "considerado" santo, neste caso, Jaime I.

Estes diversos exemplos, produzidos em sua maioria no Principado de Catalunha e no Reino de Valência, territórios da Coroa de Aragão, são alguns dos quais a presença de São Jorge foi manifestada, recuperada, utilizada e institucionalizada na literatura nos respectivos contextos de composição de cada documento. Através delas podemos perceber a relação existente entre este personagem e as terras da Coroa de Aragão. Por meio de sua análise podemos observar a presença constante e arraigada de São Jorge na memória coletiva dos cronistas, os quais associavam o santo ao território, identificando-o ao lado de reis, nos momentos decisivos das batalhas, na ordenação da corte e no estabelecimento de festas em sua comemoração.

\section{Conclusão}

O mito de São Jorge foi construído paulatinamente nas terras do ocidente medieval. Desde os primeiros escritos cristãos, a presença do santo se fez constante nos livros e nos escritos bíblicos, o que serviu para estabelecer o seu personagem na cultura ocidental. Seu culto na Coroa de Aragão foi estabelecido pouco a pouco, durante mais de cinco séculos, até sua festa ser reconhecida oficialmente pelo papado durante o pontificado de Clemente IX. Não podemos esquecer que sua representação foi construída de uma forma diversa, como as manifestações literárias, artísticas e a oposição a outros personagens da época, como Santiago Matamoros.

A construção da representação de São Jorge na Coroa de Aragão foi feita com o auxílio de materiais produzidos neste território, os quais serviam não somente para representá-lo mas também para associá-lo aos diferentes contextos históricos da Coroa. Tal produção fez com que o santo fosse considerado onipresente na cultura escrita da Coroa de Aragão, que seu personagem fosse associado diretamente à realeza e aos condes-reis e que, posteriormente, fosse instituído na produção literária do território. As representações da 
vida deste santo foram estabelecidas lentamente no imaginário coletivo do território da Coroa de Aragão através de manifestações escritas, artísticas, culturais e literárias, ampliadas e modificadas com o tempo. Dessa forma, sua representação arraigou-se na memória coletiva e fez com que o mesmo fosse constantemente recordado nos contextos em que a necessidade identitária fora necessária.

\section{REFERÊNCIAS}

Fontes primárias

AlVIRA CABReR, M. Pedro el Católico, Rey de Aragón y Conde de Barcelona (1196-1213). Documentos, Testimonios y Memoria Histórica. Tomo I. Fuentes Históricas Aragonesas 52. Zaragoza: Institución "Fernando el Católico" (C. S. I. C.), 2010.

Crònica de Ramon Muntaner. In: Les Quatre Grans Cròniques. Revisió del text, pròlegs i notes per Ferran Soldevila. Barcelona: Editorial Selecta, 1971.

Crónica de San Juan de la Peña (Versión aragonesa). Edición crítica a cura de Carmen Orcastegui Gros. Zaragoza: Institución Fernando el Católico, 1985.

Dietaris de la Generalitat de Catalunya. Col-lecció de 10 Volums. Director: Josep Maria Sans i Travé; a cura de Lluïsa Cases i Loscos, Josep Fernàndez i Trabal; Laureà Pagarolas i Sabaté. Barcelona: Generalitat de Catalunya/Gráficas Almogávares, 1994.

FERNÃO LOPES. Crónica de D. João I. Volume 1. Barcelos: Livraria Civilização, 1994.

JAUME DE VORÀGINE. Llegenda Àuria (a cura de Nolasc Rebull). Olot: Aubert Impressor, 1976.

Llibre dels Fets del Rei En Jaume (a cura de Jordi Bruguera). Volum. II. Barcelona: Editorial Barcino, 1991.

Ordinacions de la Casa i Cort de Pere el Cerimoniós. Edició a cura de Francisco M. Gimeno, Daniel Gozalbo i Josep Trenchs. Estudi introductori de Francisco M. Gimeno Blay. València: Publicacions Universitat de València, 2009.

Sumari d'Espanya per Berenguer de Puigpardines. Edició a cura de Joan Iborra. València: Servei de Publicacions de la Universitat de València, 2000.

VICENT FERRER. Sermons de Quaresma. Volum. II. Edició M. Sanchis Guarner. València: Albatros, 2003.

Bibliografia 
ANGLÈS, H. L'ordre de Sant Jordi durant els segles XIII-XIV i la devoció dels reis d'Aragó al sant cavaller. In: Miscel/lània Fontserè. Barcelona: Gustavo Gili, 1961, p. 41-65.

ARMANGUÉ I HERRERO, J. Primers contactes culturals entre els Països Catalans i Sardenya. In: Estudis sobre la cultura catalana a Sardenya. Barcelona: Institut d'Estudis Catalans, 2001, p. 15-28.

ASSMANN, J. Collective Memory and Cultural Identity. New German Critique, 65, 1995, p. 125-133.

BARAUT, C. Els orígens del culte de Sant Jordi a Catalunya i al bisbat d'Urgell, abans del segle XII. In: BUSQUETS, J.; MARTINELL, M. Fe i Teologia en la Història. Estudis en honor del Prof. Dr. Evangelista Vilanova. Barcelona: Facultat de Teologia de Catalunya; Istituto per le scienze religiose (Bolonya); Publicacions de l'Abadia de Montserrat, 1997, p. 137-142.

BARRIGA I PÉREZ, F. Sant Jordi i Catalunya. Arrels de la identitat catalana. Madrid: Editorial Edaf, 2006.

CANELLAS LÓPEZ, Á. Leyenda, culto y patronazgo en Aragón del señor san Jorge, mártir y caballero. Revista de Historia Jerónimo Zurita, 19-20, 1966-1967, p. 7-22.

CASASNOVAS CAMPS, M. À. Història de les Illes Balears. Mallorca: Editorial Moll, 1998.

CINGOLANI, S. M. La memòria dels reis. Les Quatre Grans Cròniques i la historiografia catalana, des del segle $\mathrm{X}$ fins al XIV. Barcelona: Editorial Base, 2008.

Sant Jordi. Una llegenda mil·lenària. Barcelona: Editorial Base, 2014.

DAVIES, N. Reinos desaparecidos. La historia olvidada de Europa. Barcelona: Galaxia Gutenberg, 2013.

DOMíNGUEZ GARCÍA, J. Memorias del futuro: ideología y ficción en el símbolo de Santiago Apóstol. Madrid: Vervuert-Iberoamericana, 2008.

De Apóstol matamoros a Yllapa mataindios: dogmas e ideologías medievales en el (des)cubrimiento de América. Salamanca: Ediciones Universidad de Salamanca, 2009.

LAFUENTE GÓMEZ, M. Devoción y patronazgo en torno al combate en la Corona de Aragón: las conmemoraciones a San Jorge de 1356. Aragón en la Edad Media, 20, 2008, p. 427-444.

LE GOFF, J. L'Europe est-elle née au Moyen Âge? Paris: Éditions du Seuil, 2003.

MÁRQUEZ VILLANUEVA, F. Santiago: trayectoria de un mito. Barcelona: Edicions Bellaterra, 2004.

NORA, P. La nation-mémoire. In: Les lieux de mémoire. II. La Nation. Paris: Gallimard, 1984, p. 647658.

SÁNCHEZ SESA, R. Santiago contra São Jorge: cisma, religión y propaganda en las guerras castellanoportuguesas de la baja Edad Media. Hispania Sacra, 56/114, 2004, p. 447-464.

SAYRACH I FATJÓ, N. El patró Sant Jordi. Història, llegenda, art. Barcelona: Generalitat de Catalunya, 1996.

SOT, M. Peregrinación. In: ; SCHMITT, J.-C. (eds). Diccionario razonado del Occidente medieval. Madrid: Ediciones Akal, 2003, p. 646-654. 
SOUZA, G. Q. de. A mentalidade de cruzada na conquista de México-Tenochtitlán (1519-1521). Dissertação de Mestrado (2010). Universidade Federal de São João del Rey - Programa de Pós-Graduação em História, 2010.

TASIS I MARCA, R. El segle XIV - Pere, el Cerimoniós i els seus fills. In: Història de Catalunya - IV. Barcelona: Cupsa Editorial Planenta S. A., 1979. 